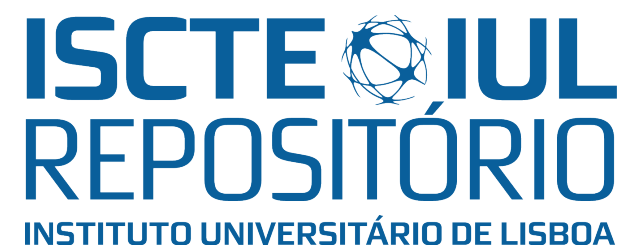

\title{
Repositório ISCTE-IUL
}

\section{Deposited in Repositório ISCTE-IUL:}

2018-12-04

\section{Deposited version:}

Publisher Version

Peer-review status of attached file:

Peer-reviewed

\section{Citation for published item:}

Gonçalves, V. (2018). Uncertain risk assessment and management: case studies of the application of the precautionary principle in Portugal. In 27th Annual Conference of the Society for Risk Analysis Europe, Risk \&amp; Uncertainty - From Critical Thinking to Practical Impact. Östersund

\section{Further information on publisher's website:}

$--$

\section{Publisher's copyright statement:}

This is the peer reviewed version of the following article: Gonçalves, V. (2018). Uncertain risk assessment and management: case studies of the application of the precautionary principle in Portugal. In 27th Annual Conference of the Society for Risk Analysis Europe, Risk \&amp; Uncertainty - From Critical Thinking to Practical Impact. Östersund. This article may be used for non-commercial purposes in accordance with the Publisher's Terms and Conditions for self-archiving.

\section{Creative Commons CC BY 4.0}

The full-text may be used and/or reproduced, and given to third parties in any format or medium, without prior permission or charge, for personal research or study, educational, or not-for-profit purposes provided that:

- a full bibliographic reference is made to the original source

- a link is made to the metadata record in the Repository

- the full-text is not changed in any way

The full-text must not be sold in any format or medium without the formal permission of the copyright holders. 
The application of the precautionary principle in the assessment and management of uncertain and potentially serious risks to environment or to public health has shown some ambiguity in the interpretation of the concept of precaution, insufficient knowledge of the potential effects of activities that may cause risk and lack of mechanisms and operational frameworks to support decisions. This has hindered the functioning of administrative justice and generated discretion and unpredictability in the decision process. This study intends to clarify how the precautionary principle has been interpreted and applied by the courts in Portugal in the analysis of conflicts associated with the existence of uncertain risks to the environment or to public health and to contribute to the debate on when and how to apply precautionary measures. To this end, a recent set of relevant court cases is considered in areas involving public health and environmental risks and the application of the precautionary principle. The decisions of the courts and their reasons in the different judicial bodies are analyzed. In order to evaluate the degree of consistency of the courts' decisions in relation to comparable risks and their proportionality with respect to the seriousness of risks, a theoretical framework was developed based on the level of seriousness of risk, the level of evidence required and the level of severity of precautionary measures. Different positions among courts were observed, with contradictory arguments in the same case or in similar cases. The existing risks are admitted but with different levels of seriousness, requiring different levels of evidence and giving priority to different interests. Therefore, in order to counteract the lack of clear and insufficient information on existing uncertainties, leading to the perception of different levels of seriousness of risks and to contradictory decisions, more explicit legal requirements and criteria are proposed for the analysis of uncertain risks and the balancing of interests in different areas of activity and also for the proportionality of the decisions. In this context, courts should have the technical support of high quality scientific expertise in the analysis of environmental and economic information. 